\title{
Self-assembly of single walled carbon nanotubes onto cotton to make conductive yarn
}

\author{
Wei Zhang ${ }^{\mathrm{a}, \mathrm{b}, *}$, Yee Yuan Tan ${ }^{\mathrm{a}}$, Chengwei $\mathrm{Wu}^{\mathrm{c}}$, S. Ravi P. Silva ${ }^{\mathrm{a}}$
}

\section{Figures}

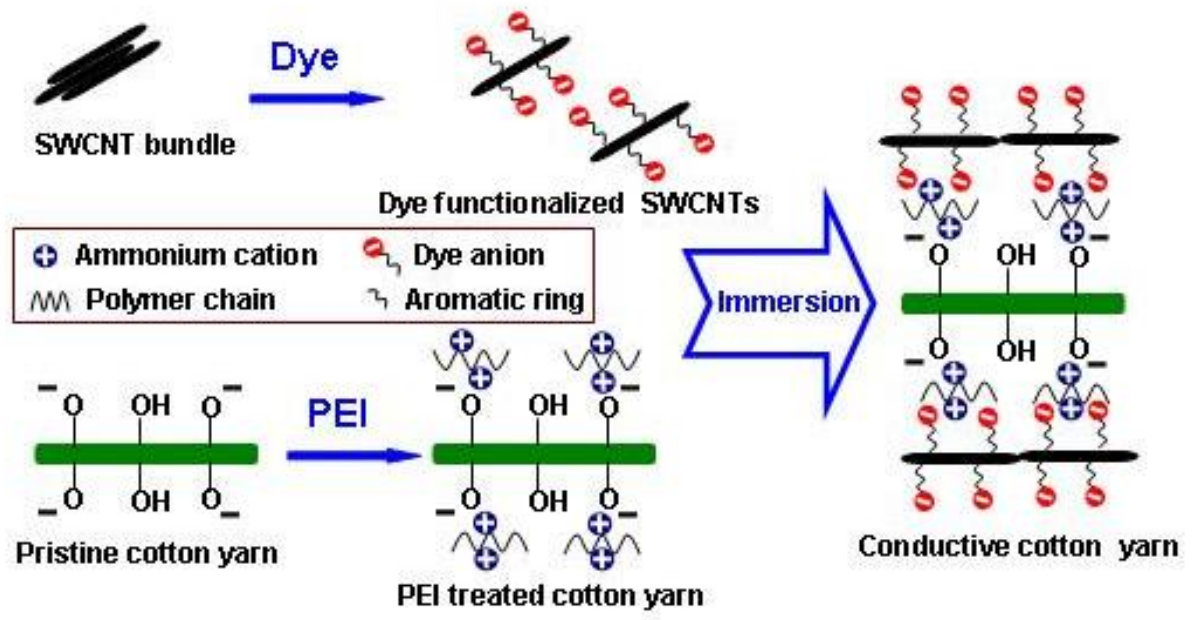

Fig. 1. Schematic illustration of the experimental principle.

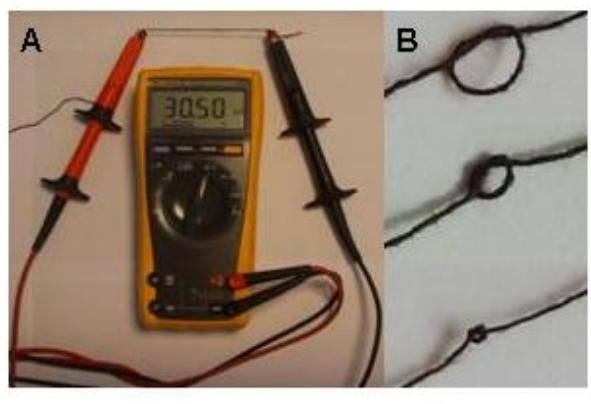

(I)
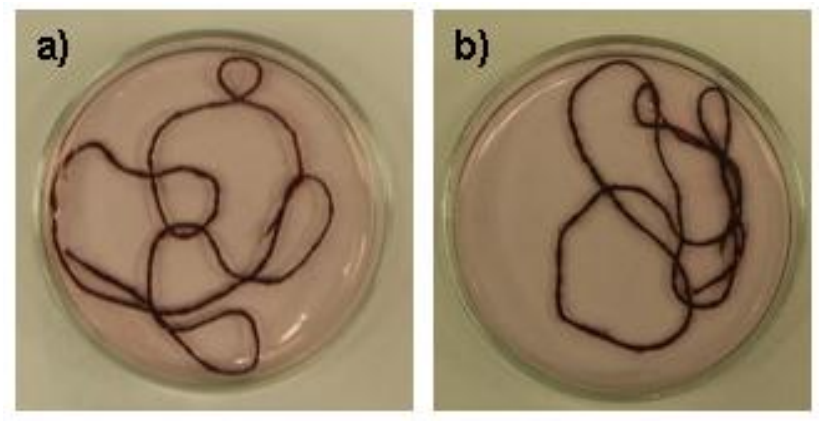

(II)

Fig. 2(I). (A) Resistance measurement of one SWCNT functionalized thread; (B) Tying knots in the

SWCNT functionalized threads does not alter the measured electrical resistance, showing the SWCNTs to be well adhered and uniform across the cross-section of the threads. Fig. 2(II) Photos of functionalized threads after heat treatment in DI water (a) and ethanol (b). 

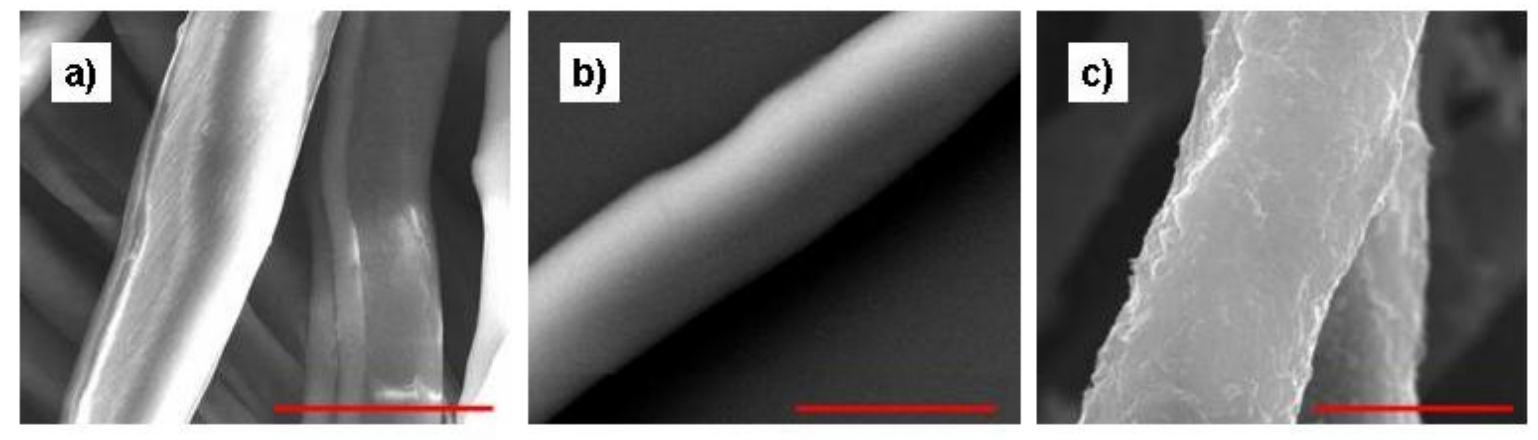

Fig. 3. SEM images of (a) pristine cotton fibre, (b) PEI treated cotton fibre and (c) SWCNT functionalized cotton fibre, with scale bar being $20 \mu \mathrm{m}$.

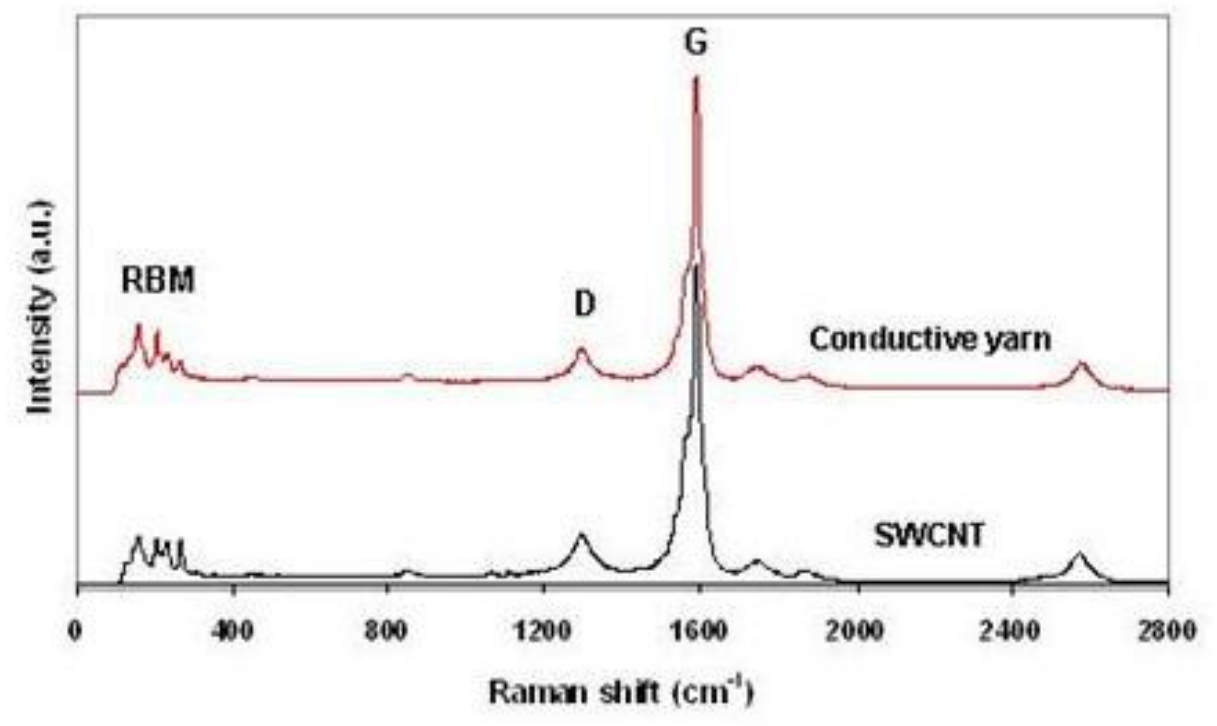

Fig. 4. Raman spectra of conductive yarn and SWCNTs (excitation at $782 \mathrm{~nm}$ ). 

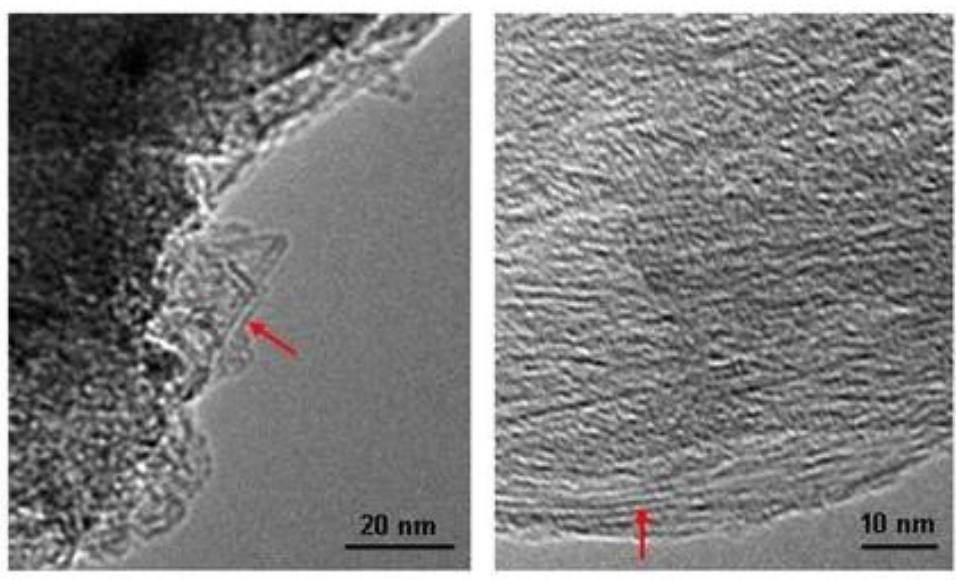

Fig. 5. TEM images of SWCNTs on conductive yarn.

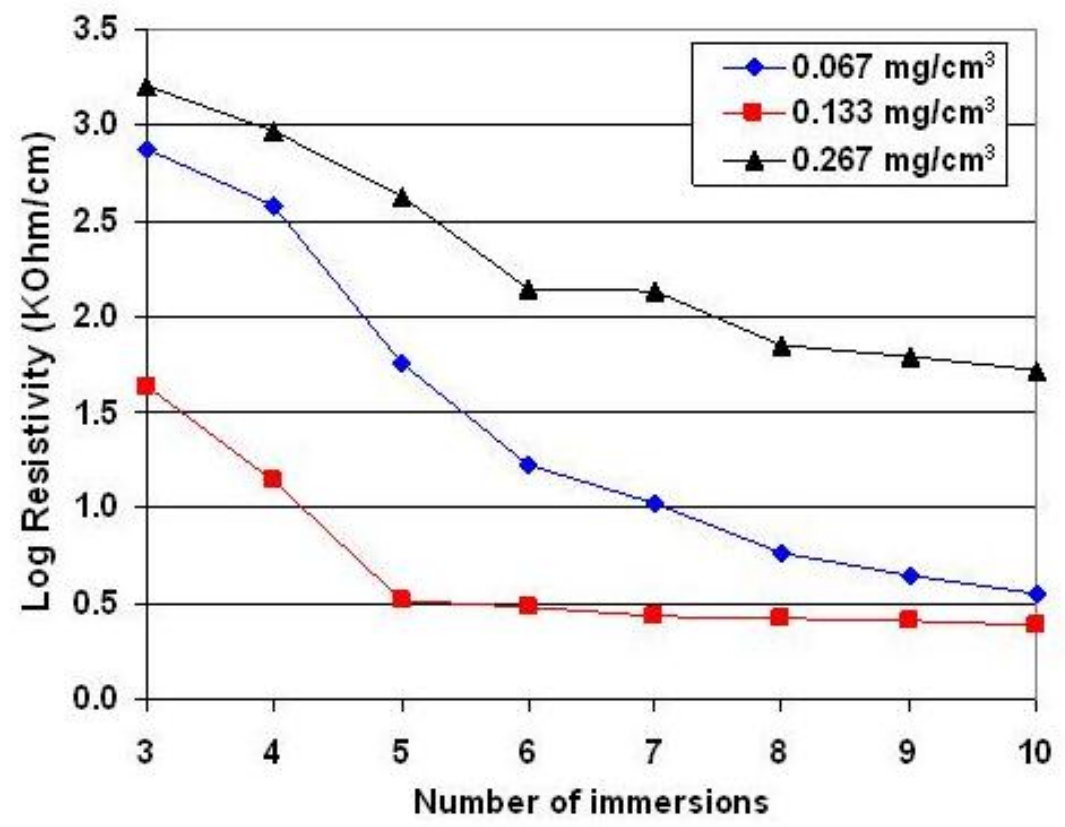

Fig. 6. Dependence of electrical resistivity on number of immersion and dye concentration (SWCNT concentration: $0.133 \mathrm{mg} / \mathrm{cm}^{3}$ ). 
a)
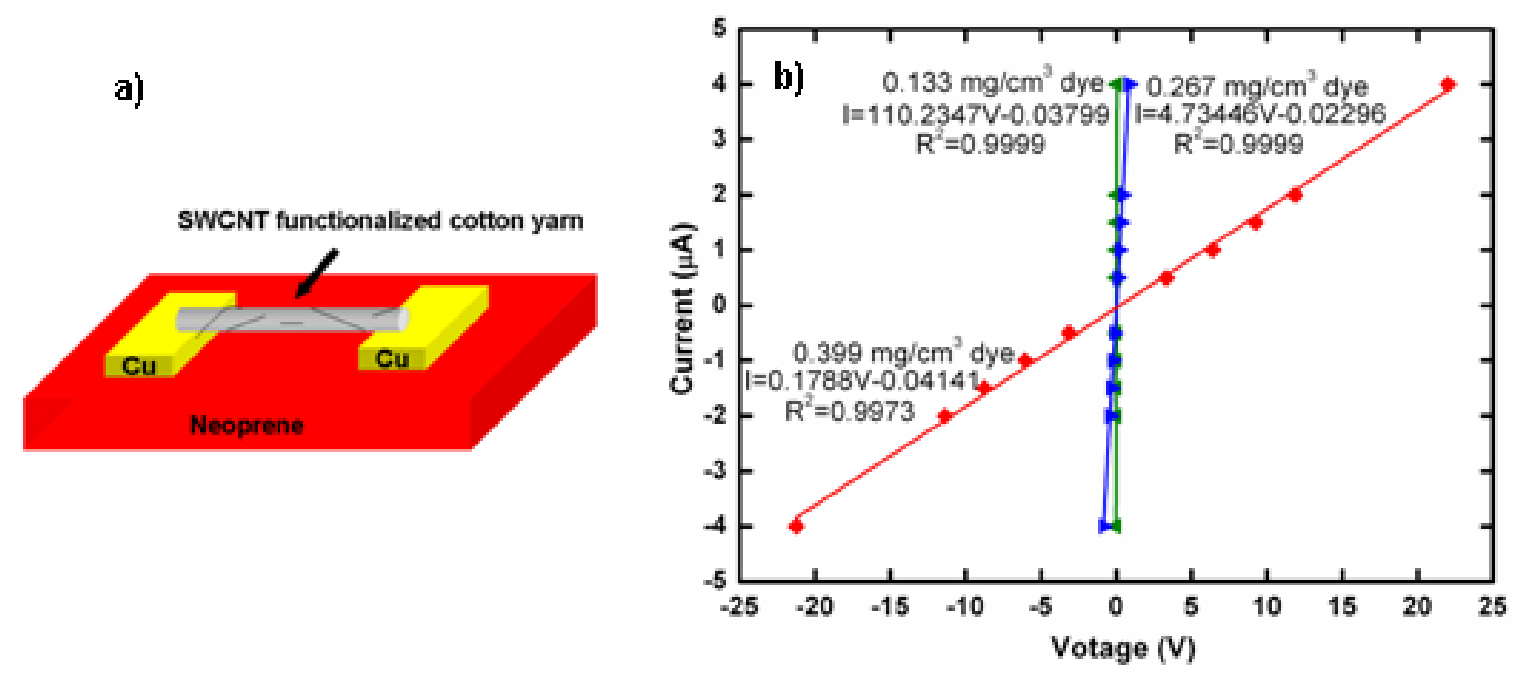

Fig. 7. (a) Schematic of chemiresistor configuration with the SWCNT functionalized cotton yarn contacting two electrodes on a neoprene rubber substrate; (b) I-V curves of sensors. The initial resistance values of sensors with yarn functionalized with $0.133,0.267,0.399 \mathrm{mg} / \mathrm{cm}^{3}$ dye solutions are around $9 \mathrm{k} \Omega, 230 \mathrm{k} \Omega$, and $6 \mathrm{M} \Omega$, respectively.
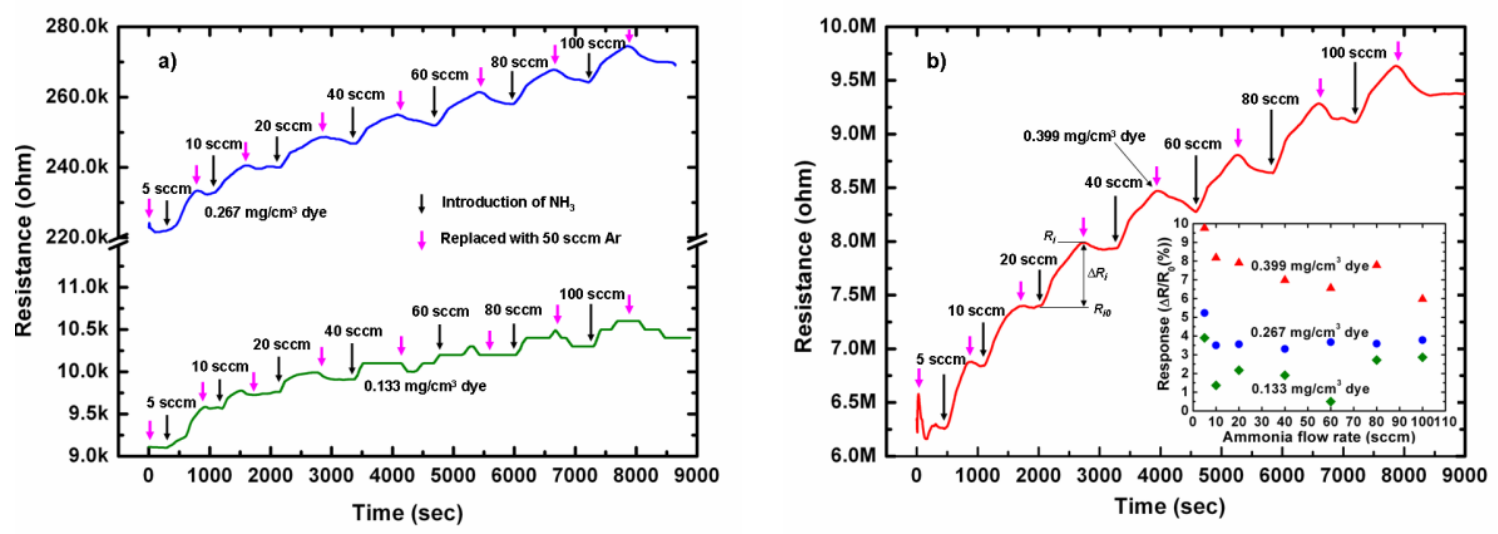

Fig. 8. Change of electrical resistance between two electrodes with the injection of ammonia gas at various flow rates for (a) 0.133 and $0.267 \mathrm{mg} / \mathrm{cm}^{3}$; (b) $0.399 \mathrm{mg} / \mathrm{cm}^{3}$ dye functionalized sensors (note different scales for y axis). Inset to (b): response of sensors at different ammonia flow rates. 